\title{
REVIEW
}

\section{The genetics of inherited macular dystrophies}

\author{
M Michaelides, D M Hunt, A T Moore
}

J Med Genet 2003;40:641-650

The inherited macular dystrophies comprise a heterogeneous group of disorders characterised by central visual loss and atrophy of the macula and underlying retinal pigment epithelium (RPE). The different forms of macular degeneration encompass a wide range of clinical, psychophysical and histological findings. The complexity of the molecular basis of monogenic macular disease is now beginning to be elucidated with the identification of many of the disease-causing genes. Age related macular degeneration (ARMD), the leading cause of blind registration in the developed world, may also have a significant genetic component to its aetiology. Genes implicated in monogenic macular dystrophies are good candidate susceptibility genes for ARMD, although to date, with the possible exception of $A B C A 4$, none of these genes have been shown to confer increased risk of ARMD. The aim of this paper is to review current knowledge relating to the monogenic macular dystrophies, with discussion of currently mapped genes, chromosomal loci and genotype-phenotype relationships. Inherited systemic disorders with a macular dystrophy component will not be discussed.

See end of article for authors' affiliations

Correspondence to Professor Moore, Institute of Ophthalmology,

University College London,

11-43 Bath Street, London

ECIV 9EL, UK:

tony.moore@ucl.ac.uk
$\mathrm{T}$ he inherited macular dystrophies are characterised by bilateral visual loss and the finding of generally symmetrical macular abnormalities on ophthalmoscopy. The age of onset is variable, but most present in the first two decades of life. There is considerable clinical and genetic heterogeneity; macular dystrophies showing autosomal dominant, autosomal recessive, $X$ linked recessive and mitochondrial inheritance have all been reported. Most of the disorders are uncommon and have been incompletely characterised, and thus classification based on phenotypic characteristics is at present unsatisfactory.

A classification based upon molecular pathology would be more satisfactory but research into the molecular genetic basis of this group of disorders is still at an early stage. Seven diseasecausing genes have been identified to date (table 1) and their identification has provided new insights into the pathogenesis of macular degeneration. Age related macular degeneration (ARMD) also has a genetic contribution to its aetiology. Approximately $20 \%$ of patients have a positive family history ${ }^{1}$ and twin studies support a strong genetic component. ${ }^{2}$ Genes implicated in monogenic macular dystrophies are potential candidates for genes conferring risk for ARMD.

\section{AUTOSOMAL RECESSIVE INHERITANCE Stargardt disease and fundus flavimaculatus}

Stargardt macular dystrophy (STGD) is the most common inherited macular dystrophy with a prevalence of 1 in 10000 and an autosomal recessive mode of inheritance. It shows a very variable phenotype with a variable age of onset and severity. Most cases present with central visual loss in early teens and there is typically macular atrophy with white flecks at the level of the RPE at the posterior pole on ophthalmoscopy (fig 1). Fluorescein angiography classically reveals a dark or masked choroid. ${ }^{34}$ The reduced visualisation of the choroidal circulation in the early phase of fundus fluorescein angiography (FFA) is believed to be secondary to excess lipofuscin accumulation in the RPE, thereby obscuring fluorescence emanating from choroidal capillaries. ${ }^{34}$ The retinal flecks appear hypofluorescent on FFA early in their evolution but at a later stage they appear hyperfluorescent due to RPE atrophy. Recently a new method has been developed to visualise the RPE, autofluorescence imaging, which takes advantage of its intrinsic fluorescence derived from lipofuscin. ${ }^{567}$ Autofluorescence imaging with a confocal scanning laser ophthalmoscope can provide useful information about the distribution of lipofuscin in the RPE, and give indirect information on the level of metabolic activity of the RPE which is largely determined by the rate of turnover of photoreceptor outer segments. ${ }^{7}$ There is evidence of continuous degradation of autofluorescent material in the RPE. ${ }^{7}$ Progressive loss of lipofuscin occurs when there is reduced metabolic demand due to photoreceptor cell loss, which appear as areas of decreased autofluorescence (AF). ${ }^{7}$ Areas of increased AF correspond to a group of RPE cells containing higher quantities of lipofuscin than their neighbours and may represent areas at high risk for photoreceptor cell

Abbreviations: adMD, autosomal dominant atrophic macular degeneration; $A F$, autofluorescence; $A R M D$, age related macular degeneration; $A V M D$, adult vitelliform macular dystrophy; $C A C D$, central areolar choroidal dystrophy; CORD, cone-rod dystrophy; EOG, electrooculography; ERG, electroretinography; FFA, fundus fluorescein angiography; PBCRA, progressive bifocal chorioretinal atrophy; $R P$, retinitis pigmentosa; $R P E$, retinal pigment epithelium; SFD, Sorsby fundus dystrophy; SRNVM, subretinal neovascular membrane; VEGF, vascular endothelial growth factor 


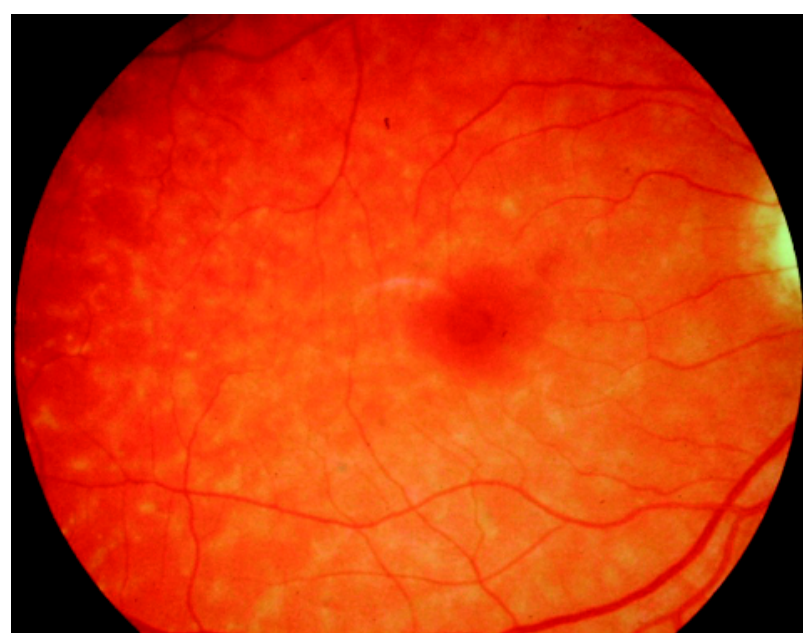

Figure 1 Stargardt disease. Fundus photograph of a right eye showing white flecks at the level of the RPE at the posterior pole. There is early macular atrophy.

loss. ${ }^{8}$ It has been demonstrated histologically that the number of photoreceptor cells is reduced in the presence of increased quantities of lipofuscin in the RPE, leading to the proposal that autofluorescent material may accumulate prior to cell death. ${ }^{9}$ The abnormal accumulation of lipofuscin, the presence of active and resorbed flecks, and RPE atrophy all contribute to a characteristic appearance on fundus autofluorescence imaging in STGD. ${ }^{10}$

Histopathology of donated eyes has revealed that changes in the RPE begin near the equatorial peripheral retina and include increasingly excessive lipofuscin content and cell loss towards the macula. The changes in the retina parallel those in the RPE, including accumulation of lipofuscin in photoreceptor inner segments, loss of photoreceptors, and reactive Muller cell hypertrophy. Scanning electron microscopy shows a progressively marked heterogeneity in the size of RPE cells. ${ }^{112}$

Stargardt disease may also present in adult life when the visual loss may be milder. When the retinal flecks are seen without atrophy the term fundus flavimaculatus (FFM) is often used to describe the phenotype but it appears that Stargardt disease and FFM are caused by mutations in the same gene and both patterns may be seen within the same family. In a recent detailed phenotypic study, based on electroretinography (ERG) findings, patients with STGD/FFM could be classified into 3 groups. ${ }^{10}$ In group 1 , there was severe pattern ERG abnormality with normal scotopic and full-field ERGs. In group 2, there was additional loss of photopic function, and in group 3, there was loss of both photopic and scotopic function. Differences among groups were not explained on the basis of differences in age of onset or duration of disease, suggesting that these electrophysiological groups may represent different phenotypic subtypes, and thereby be useful in helping to provide an accurate prognosis. ${ }^{10}$ Patients in group 1 generally had better visual

Table 1 Chromosomal loci and causative genes in inherited macular dystrophies

\begin{tabular}{|c|c|c|c|c|}
\hline $\begin{array}{l}\text { Macular dystrophy; OMIM } \\
\text { number }\end{array}$ & Mode of inheritance & Chromosome locus & Mutated gene & References \\
\hline $\begin{array}{l}\text { Stargardt disease/fundus } \\
\text { flavimaculatus; } \\
248200\end{array}$ & Autosomal recessive & 1p21-p22 (STGD1) & $A B C A 4$ & 13,14 \\
\hline $\begin{array}{l}\text { Stargardt-like macular } \\
\text { dystrophy; } \\
600110\end{array}$ & Autosomal dominant & $6 q 14$ (STGD3) & ELOVL4 & 42,44 \\
\hline $\begin{array}{l}\text { Stargardt-like macular } \\
\text { dystrophy; } \\
603786\end{array}$ & Autosomal dominant & $4 p$ (STGD4) & PROMLI* & 43 \\
\hline $\begin{array}{l}\text { Autosomal dominant "bull's- } \\
\text { eye" macular dystrophy }\end{array}$ & Autosomal dominant & $4 p$ (MCDR2) & PROML1* & 47 \\
\hline $\begin{array}{l}\text { Best macular dystrophy; } \\
153700\end{array}$ & Autosomal dominant & $11 q 13$ & VMD2 & $51-53$ \\
\hline $\begin{array}{l}\text { Adult vitelliform dystrophy; } \\
179605\end{array}$ & Autosomal dominant & 6p21.2-cen & Peripherin/RDS & 62 \\
\hline $\begin{array}{l}\text { Pattern dystrophy; } \\
169150\end{array}$ & Autosomal dominant & 6p21.2-cen & Peripherin/RDS & $64-66$ \\
\hline $\begin{array}{l}\text { Doyne honeycomb retinal } \\
\text { dystrophy; } 126600\end{array}$ & Autosomal dominant & $2 p 16$ & EFEMP1 & 74 \\
\hline $\begin{array}{l}\text { North Carolina macular } \\
\text { dystrophy; } \\
136550\end{array}$ & Autosomal dominant & $6 q 14-q 16.2$ (MCDR1) & Not identified & $81-83$ \\
\hline $\begin{array}{l}\text { Autosomal dominant macular } \\
\text { dystrophy resembling MCDR }\end{array}$ & Autosomal dominant & 5p15.33-p13.1 (MCDR3) & Not identified & 84 \\
\hline $\begin{array}{l}\text { North Carolina-like macular } \\
\text { dystrophy associated with } \\
\text { deafness }\end{array}$ & Autosomal dominant & $14 p$ (MCDR4) & Not identified & 85 \\
\hline $\begin{array}{l}\text { Progressive bifocal } \\
\text { chorioretinal atrophy; } \\
600790\end{array}$ & Autosomal dominant & $6 q 14-q 16.2$ & Not identified & 88 \\
\hline $\begin{array}{l}\text { Sorsby's fundus dystrophy; } \\
136900\end{array}$ & Autosomal dominant & $22 q 12.1-q 13.2$ & TIMP3 & $90-92$ \\
\hline $\begin{array}{l}\text { Central areolar choroidal } \\
\text { dystrophy; } \\
215500\end{array}$ & Autosomal dominant & $\begin{array}{l}6 p 21.2 \text {-cen } \\
17 p 13\end{array}$ & $\begin{array}{l}\text { Peripherin/RDS } \\
\text { Not identified }\end{array}$ & $\begin{array}{l}100 \\
101-102\end{array}$ \\
\hline $\begin{array}{l}\text { Dominant cystoid macular } \\
\text { dystrophy; } \\
153880\end{array}$ & Autosomal dominant & $7 p 15-p 21$ & Not identified & 105 \\
\hline $\begin{array}{l}\text { Juvenile retinoschisis; } \\
312700\end{array}$ & $\mathrm{X}$ linked & Xp22.2 & XLRSI & 110 \\
\hline
\end{tabular}


acuity, more restricted distribution of flecks and macular atrophy, whereas those in group 3 had the worst visual acuity, more widespread flecks and macular atrophy was universal. ${ }^{10}$

The locus for STGD/FFM was mapped to chromosome ip using homozygosity mapping in inbred families, ${ }^{13}$ and the causative gene characterised, $A B C A 4$ (previously denoted $A B C R) .{ }^{14}$ Subsequently mutations in $A B C A 4$ have been implicated in other disorders, including retinitis pigmentosa $(\mathrm{RP})^{15}{ }^{16}$ and cone-rod dystrophy (CORD) ${ }^{1718} A B C A 4$ encodes a transmembrane rim protein located in the discs of rod and foveal cone outer segments, that is involved in ATP dependent transport of retinoids from photoreceptor to RPE. ${ }^{19-21}$ Failure of this transport results in deposition of a major lipofuscin fluorophore, A2E (N-retinylidene-N-retinylethanolamine), in the RPE. ${ }^{21}$ It is proposed that this accumulation may be deleterious to the RPE, with consequent secondary photoreceptor degeneration.

Mutation screening of patients with STGD/FFM has been performed by several groups in recent years. ${ }^{22-25}$ The high allelic heterogeneity of $A B C A 4$ is clearly demonstrated by the fact that approximately 400 sequence variations in this gene have been reported. This highlights the potential difficulties in confidently assigning disease-causing status to sequence variants detected when screening such a large (50 exons) and polymorphic gene. Nonsense mutations that can be predicted to have a major effect on the encoded protein can be confidently predicted to be disease-causing. However a major problem occurs with missense mutations since sequence variants are common in controls and therefore establishing pathogenicity may be problematic. Hence large studies assessing whether particular sequence variants are statistically more frequently seen in STGD patients than controls are likely to be helpful. ${ }^{26}$ Direct evidence of pathogenicity can be established by functional analysis of the encoded mutant protein, ${ }^{27}$ although such studies are very time consuming and labour intensive. The availability of multiple independent families with the same mutation may also provide evidence in support of disease causation.

It is currently believed that: (1) homozygous null mutations cause the most severe phenotype of autosomal recessive RP; (2) combinations of a null mutation with a moderate missense mutation result in autosomal recessive CORD, and (3) combinations of null/mild missense or two moderate missense mutations cause STGD/FFM. ${ }^{28}$

Assessment of functional activity of mutant ABCA4 transporter has been performed by Sun et al. ${ }^{27}$ For example the missense mutations, L541P and G1961E, are associated with severely reduced but not abolished ATPase activity, whereas nonsense mutations would be predicted to have a more severe effect on protein function. Such predictions and functional assay results ${ }^{27}$ have been used to establish whether genotype-phenotype correlations can be reliably made. Gerth et $a l^{29}$ have recently reported a detailed assessment of the phenotype of sixteen patients with STGD/FFM with known $A B C A 4$ mutations. Correlation between the type and combination of $A B C A 4$ mutations with the severity of the phenotype in terms of age of onset and level of photoreceptor dysfunction was possible in many cases. However in some siblings there were unexplained differences in phenotype. It has been proposed that in these instances other genes may have a modifying effect or environmental factors may have a role to play. ${ }^{30}$ This is a recurring theme in the inherited macular dystrophies, in that the underlying "genetic context" within which mutations associated with disease are expressed can influence the eventual phenotype observed. In addition, variable retinal phenotype within families may be explained by different combinations of $A B C A 4$ mutations segregating within a single family. ${ }^{31}$
The ocular phenotype in $A B C A 4$ knockout mice has been determined. Knockout mice $\left(a b c a 4^{-1-}\right)$ show delayed dark adaptation, increased all-trans-retinaldehyde (all-trans-RAL) following light exposure, and striking deposition of the major lipofuscin fluorophore, A2E, in the RPE. Delayed dark adaptation is likely to be due to the accumulation in outer segment discs of the non-covalent complex between opsin and all-trans-RAL. ${ }^{21}$ Delayed recovery of rod sensitivity after light exposure is also a clinical feature of human subjects with both STGD and ARMD. ${ }^{32}{ }^{33}$ Heterozygous loss of the ABCA4 protein has also been shown to be sufficient to cause a phenotype in mice similar to STGD and ARMD in humans. ${ }^{34}$ These data are consistent with the suggestion that the STGD carrier-state may predispose to the development of ARMD.

Light-exposed A2E-laden RPE exhibits a propensity for apoptosis especially with light in the blue part of the spectrum. $^{35}$ During RPE irradiation $(430 \mathrm{~nm})$, A2E selfgenerates singlet oxygen with the latter in turn reacting with $\mathrm{A} 2 \mathrm{E}$ to generate epoxides. ${ }^{36}$ It has been recently demonstrated that these A2E epoxides exhibit damaging reactivity towards DNA. ${ }^{37}$ Moreover, mass spectrometry revealed that the antioxidants vitamins $\mathrm{E}$ and $\mathrm{C}$ reduce $\mathrm{A} 2 \mathrm{E}$ epoxidation, with a corresponding reduction in the incidence of DNA damage and cell death. Vitamin E produced a more pronounced decrease in A2E epoxidation than vitamin C. Studies in which singlet oxygen was generated by endoperoxide in the presence of $\mathrm{A} 2 \mathrm{E}$, revealed that vitamin $\mathrm{E}$ reduced A2E epoxidation by quenching singlet oxygen. ${ }^{37}$ This study raises the exciting possibility of a simple therapy. The potential for pharmacological manipulation of ABCA4 activity has also been demonstrated by in vitro studies. ${ }^{38}$ For example, amiodarone has been found to enhance ATPase activity in vitro. ${ }^{38}$ Therefore such compounds which act to augment ABCA4-related retinoid transport may prove to be beneficial in vivo in patients with STGD or in a subset of individuals at risk for ARMD.

A different strategy of reducing A2E related toxicity, by inhibiting the formation of such lipofuscin pigments has also been reported. ${ }^{39}{ }^{40}$ It has been shown that A2E synthesis can be virtually blocked by raising $a b c a 4^{-/-}$mice in total darkness. ${ }^{39}$ Recently it has been demonstrated in the abca4 ${ }^{-/}$ mouse model that isotretinoin blocked the formation of A2E and the accumulation of lipofuscin pigments in the RPE. ${ }^{40}$ Isotretinoin (13-cis-retinoic acid) is known to slow the synthesis of 11-cis-retinaldehyde and regeneration of rhodopsin by inhibiting 11-cis-retinol dehydrogenase in the visual cycle. Light activation of rhodopsin results in the release of all-trans-RAL, which constitutes the first reactant in A2E biosynthesis. Treatment with isotretinoin, an established treatment for acne, may inhibit lipofuscin accumulation and thus delay the onset of visual loss in STGD. ${ }^{40}$ It remains to be assessed whether isotretinoin is a potential treatment for other forms of macular degeneration associated with lipofuscin accumulation.

\section{AUTOSOMAL DOMINANT INHERITANCE Autosomal dominant Stargardt-like macular dystrophy}

The clinical appearance of autosomal dominant (AD) Stargardt-like macular dystrophy is so similar to the common autosomal recessive form of the disorder that it is difficult to differentiate between them by fundus examination alone. ${ }^{41}$ However individuals reported with features of AD STGD-like dystrophy have a milder phenotype with relatively good functional vision, minimal colour vision defects and no significant electro-oculography (EOG) or ERG abnormalities. ${ }^{41}$ The "dark choroid" sign on fluorescein angiography which is typical in the recessive form, but not diagnostic, is uncommon in the dominant form of the disorder. 
Two chromosomal loci have been identified, 6q14 (STGD3) and $4 \mathrm{p}$ (STGD4). ${ }^{42} 43$ Two mutations, a 5-bp deletion and two l-bp deletions separated by four nucleotides, in the gene ELOVL4 have been associated with STGD3 and other macular dystrophy phenotypes including pattern dystrophy. ${ }^{44} 45$ ELOVL4 is expressed in the rod and cone photoreceptor inner segments. The protein product is believed to be involved in retinal fatty acid metabolism since it has significant homology to a family of proteins involved in fatty acid elongation. A missense mutation in PROML1 has recently been found to co-segregate with disease in the STGD4 pedigree (personal communication, $\mathrm{K}$ Zhang). The gene PROML1 encodes human prominin (mouse)-like 1, which belongs to the prominin family of five-transmembrane domain proteins. PROML1 is expressed in retinoblastoma cell lines and adult retina, and the product of the mouse orthologue (prom) is concentrated in membrane evaginations at the base of the outer segments of rod photoreceptors. $^{46}$ A homozygous mutation in PROML1 has been identified in an Indian pedigree with an autosomal recessive retinal dystrophy. The mutation results in the production of a truncated protein and functional studies in transfected $\mathrm{CHO}$ cells has demonstrated that the truncated prominin protein fails to reach the cell surface, indicating that the loss of prominin may lead to retinal degeneration via the impaired generation of evaginations or conversion to outer segment disks. ${ }^{46}$

We have recently reported a British family with an autosomal dominant "Bull's-Eye" macular dystrophy (MCDR2) also mapping to chromosome $4 \mathrm{p},{ }^{47}$ and overlapping the STGD4 disease interval reported by Kniazeva et al. ${ }^{43}$ The MCDR2 phenotype that we have described is clinically distinct from that of STGD4 in that retinal flecks are absent and there is also no evidence of a dark choroid on fluorescein angiography, both of which are prominent features of the STGD4 family. We have however identified the same missense mutation in PROML1 as has been found in the STGD4 pedigree (unpublished data). This therefore represents another example where the eventual macular dystrophy phenotype observed would appear to be dependent on the genetic context/background within which a mutation in a particular gene is expressed.

\section{Best disease (vitelliform macular dystrophy)}

Best disease is a dominantly inherited macular dystrophy which is characterised clinically by the classical feature of a round or oval yellow subretinal macular deposit. The yellow material is gradually resorbed over time, leaving an area of

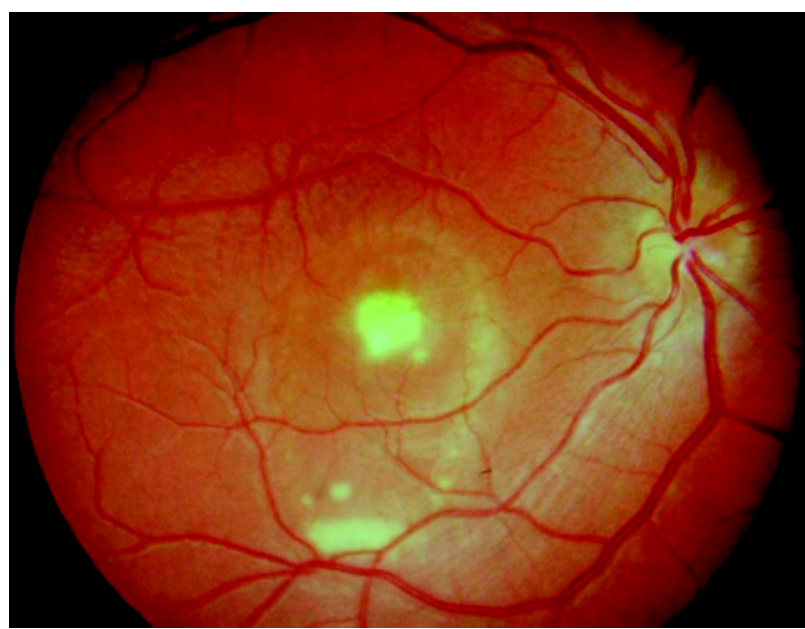

Figure 2 Best disease. Fundus photograph of a right eye showing a partially resorbed yellow subretinal macular deposit.
RPE atrophy and often subretinal fibrosis (fig 2). The flash ERG is normal but the EOG shows a very reduced or absent light rise indicating that there is widespread dysfunction of the RPE. ${ }^{48}$ In common with STGD, histopathology of donated eyes from patients with Best disease has shown accumulation of lipofuscin throughout the RPE. ${ }^{49}{ }^{50}$ Although the ophthalmoscopic abnormality is usually confined to the macular region, this evidence of more widespread retinal involvement is in common with the majority of inherited macular dystrophies described to date. The disease shows very variable expressivity. Most individuals carrying mutations in the VMD2 gene on chromosome $11 \mathrm{q} 13^{51-53}$ have an abnormal EOG, but the macular appearance may be normal in some. ${ }^{54}$ There is only one individual reported with evidence of non-penetrance, in that he is a mutant VMD2 gene carrier with a normal fundus examination and normal EOG. ${ }^{55}$ The visual prognosis in Best disease is surprisingly good, with most patients retaining reading vision into the fifth decade of life or beyond. Family members who carry a mutation in the $V M D 2$ gene and who have minimal macular abnormality or a normal fundus appearance (but abnormal EOG) in early adult life, usually retain near normal visual acuity long term.

The protein product of VMD2, bestrophin, has been localised to the basolateral plasma membrane of the RPE where it forms a component of a chloride channel responsible for maintaining chloride conductance across the basolateral membrane of the RPE. ${ }^{56} 57$ This chloride current regulates fluid transport across the RPE, and it has been suggested following optical coherence tomography of patients with Best's, that impaired fluid transport in the RPE secondary to abnormal chloride conductance may lead to accumulation of fluid and/or debris between RPE and photoreceptors and between RPE and Bruch's membrane, leading to detachment and secondary photoreceptor degeneration. ${ }^{58-60}$

The variable expression of Best disease remains unexplained, and here once again, other genes in addition to $V M D 2$, and/or environmental influences may play a role in the wide range of clinical expression seen.

\section{Adult vitelliform macular dystrophy}

Adult vitelliform macular dystrophy (AVMD) is often confused with Best disease, although as the name suggests it has a later onset, lacks the typical course through different stages of macular disease seen in classical Best's, and the electro-oculogram (EOG) is usually normal. ${ }^{61}$ The typical clinical appearance is of bilateral, round or oval, yellow, symmetrical, sub-retinal lesions, typically one third to one half optic disc diameter in size.

Mutations in the peripherin/RDS gene on chromosome $6 \mathrm{p}$ have been identified in AVMD. ${ }^{62}$ It has been proposed that mutations in peripherin/RDS are present in approximately $20 \%$ of patients with AVMD, ${ }^{62}$ which implies further genetic heterogeneity.

\section{Pattern dystrophy}

The pattern dystrophies are a group of inherited disorders of the RPE which are characterised by bilateral symmetrical yellow-orange deposits at the macula in various distributions, including butterfly or reticular-like patterns. These dystrophies are often associated with a relatively good visual prognosis, although in some cases a slowly progressive loss of central vision can occur. There is usually psychophysical or electrophysiological evidence of widespread photoreceptor dysfunction. ${ }^{63}$ Electrophysiological findings usually reveal abnormal pattern ERG, normal flash ERG, but abnormal EOG.

Mutations in the peripherin/RDS gene on chromosome $6 \mathrm{p}$ have been identified in patients with pattern dystrophies, ${ }^{64-66}$ and have also been implicated in autosomal dominant RP. ${ }^{67} 68$ The RDS gene was originally identified in a strain of mice 
with a photoreceptor degeneration known as "retinal degeneration, slow" (rds). Subsequently, the orthologous human peripherin/RDS gene was shown to cause autosomal dominant RP. ${ }^{67}{ }^{68}$ Mutation in codon 172 of peripherin/RDS has also been implicated in autosomal dominant macular dystrophy. ${ }^{69}$ The peripherin/RDS protein is a membrane associated glycoprotein restricted to photoreceptor outer segment discs in a complex with ROMl. It may function as an adhesion molecule involved in the stabilisation and maintenance of a compact arrangement of outer segment discs. ${ }^{70}$ Peripherin has also been shown to interact with the GARP domain (glutamic acid- and proline-rich region) of the beta-subunit of rod cGMP-gated channels, in a complex including the $\mathrm{Na} / \mathrm{Ca}-\mathrm{K}$ exchanger. ${ }^{71}$ This interaction may have a role in anchoring the channel-exchanger complex in the rod outer segment plasma membrane. Weleber et al described a single family in which a 3-bp deletion in peripherin/RDS resulted in retinitis pigmentosa, pattern dystrophy and FFM in different individuals. ${ }^{66}$ This represents a further example of the likely modifying effects of genetic background or environment.

The rds mouse, which is homozygous for a null mutation in peripherin/RDS, is characterised by a complete failure to develop photoreceptor discs and outer segments, downregulation of rod opsin expression, and apoptotic loss of photoreceptor cells. Ali et $a l^{72}$ have demonstrated that subretinal injection in these mice of recombinant adenoassociated virus encoding a peripherin/RDS transgene, resulted in the generation of outer segment structures and formation of new stacks of discs containing both peripherin/RDS and rhodopsin. Moreover, electrophysiological function was also preserved. This study demonstrates in an animal model the efficacy of in vivo gene transfer to restore structure and more importantly function. ${ }^{72}$ Further assessment of this model has shown that the potential for ultrastructural improvement is dependent upon the age at treatment, but the effect of a single injection on photoreceptor ultrastructure may be long lasting. ${ }^{73}$ These findings suggest that successful gene therapy in patients with photoreceptor defects may ultimately depend upon intervention in early stages of disease and upon accurate control of transgene expression.

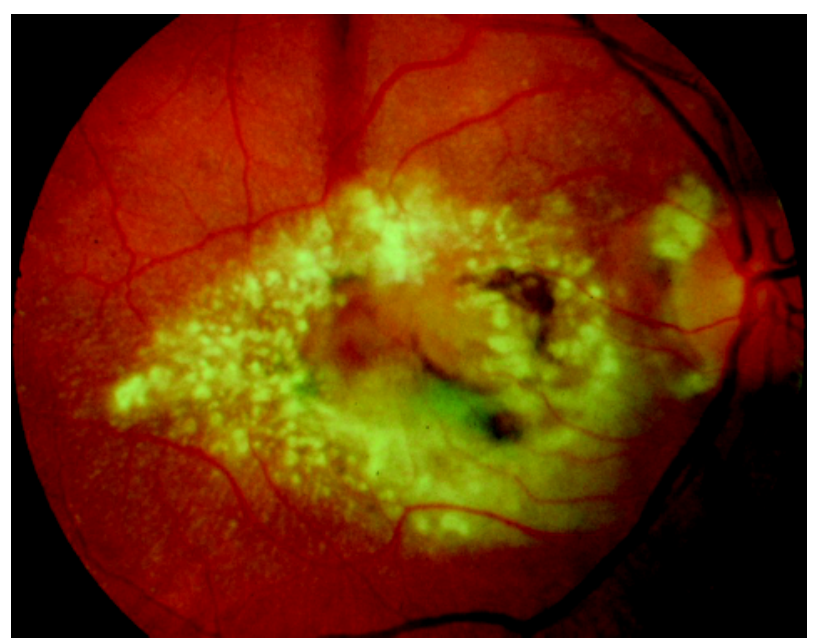

Figure 3 Doyne honeycomb retinal dystrophy. Fundus photograph of a right eye showing multiple drusen-like deposits at the macula and around the optic disc. Small drusen-like deposits can also be seen to radiate from the periphery of the main drusen mass. The established complication of subretinal neovascular membrane (SRNVM) is present centrally.

\section{Doyne honeycomb retinal dystrophy (malattia} leventinese; autosomal dominant drusen)

In this disorder small round yellow-white deposits under the RPE are characteristically distributed at the macula and around the optic disc, and begin to appear in early adult life (fig 3). Visual acuity is maintained through the fifth decade, but patients usually become legally blind by the seventh decade. Visual loss is usually due to macular atrophy, but less commonly may follow subretinal neovascular membrane (SRNVM). The presence of drusen-like deposits makes this dystrophy potentially very relevant to ARMD.

A single mutation, Arg-345-to-Trp (R345W) in the gene EFEMPI on chromosome $2 \mathrm{p}$ has been identified in the majority of patients with dominant drusen..$^{74}$ EFEMPI is a widely expressed gene of unknown function. Based on its sequence homology to the fibulin and fibrillin gene families, EFEMPI is predicted to be an extracellular matrix glycoprotein, but otherwise is uncharacterised. However, it has been recently proposed that misfolding and aberrant accumulation of EFEMPl within RPE cells and between the RPE and Bruch's membrane may underlie drusen formation in Doyne Honeycomb retinal dystrophy and ARMD. EFEMPI itself does not appear to be a major component of the drusen. ${ }^{75}$

Genetic heterogeneity in autosomal dominant drusen has been suggested by Tarttelin $e t a^{76}$, since they found that only seven of the 10 families $(70 \%)$ and one of the 17 sporadic patients $(6 \%)$ investigated had the R345W mutation. No other EFEMP1 mutation was detected in these patients. Other families showing linkage to chromosome 2 pl6 raise the possibility of an upstream EFEMPI promoter mutation or a second dominant drusen gene at this locus.

\section{Autosomal dominant drusen and macular degeneration (DD)}

Stefko et $a l^{77}$ have described a highly variable clinical phenotype in a North American family with an autosomal dominant drusen disorder with macular degeneration (DD). Most young adults had fine macular drusen and good vision. Affected infants and children may have congenital atrophic maculopathy and drusen. There was also evidence of progression in late adulthood with moderate visual loss.

The gene for the disease has been mapped to chromosome $6 \mathrm{ql} 4$ and appears to be adjacent to but distinct from the locus for North Carolina macular dystrophy (MCDR1). ${ }^{78}$ The disease interval overlaps with that of STGD3 and an autosomal dominant atrophic macular degeneration (adMD), ${ }^{79}$ raising the possibility that they may be allelic disorders. However the phenotype of DD differs from that of STGD3 and adMD. Macular drusen are a hallmark of DD, whilst RPE atrophy and subretinal flecks are prominent features of STGD3 and adMD. The true situation will only be resolved by the identification of the underlying genetic mutations.

\section{North Carolina macular dystrophy}

North Carolina macular dystrophy (MCDRl) is an autosomal dominant disorder which is characterised by a variable macular phenotype and a non-progressive natural history. Bilaterally symmetrical fundus appearances in MCDRl range from a few small (less than $50 \mu \mathrm{m}$ ) yellow drusen-like lesions in the central macula (grade 1) to larger confluent lesions (grade 2) and macular colobomatous lesions (grade 3) (fig 4). ${ }^{80}$ Occasionally MCDRl is complicated by SRNVM formation at the macula. EOG and ERG are normal indicating that there is no generalised retinal dysfunction.

Linkage studies have mapped MCDRl to a locus on chromosome 6q16. To date, MCDRl has been described in various countries and no evidence of genetic heterogeneity has been reported. ${ }^{81-83}$ The identification of the gene 


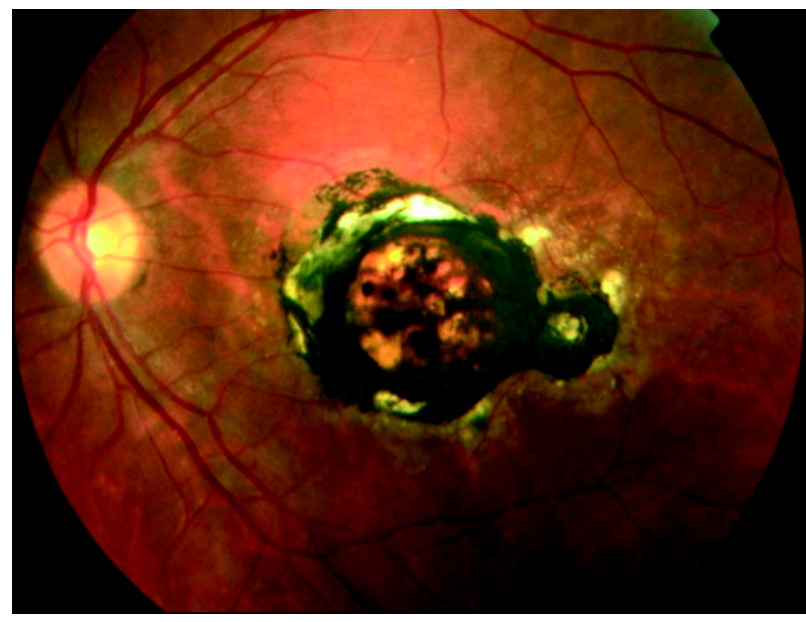

Figure 4 North Carolina macular dystrophy. Fundus photograph of a left eye showing macular atrophy and hyperpigmentation with surrounding drusen-like deposits.

responsible for this disorder is keenly awaited as it will help to improve our understanding of the pathogenesis of drusen and SRNVM.

An early onset autosomal dominant macular dystrophy (MCDR3) resembling MCDRl has been recently mapped to chromosome $5 p{ }^{84}$ Linkage to the MCDRl locus was excluded. The only significant differences in the two phenotypes is that in MCDR3 colour vision is abnormal in the majority of affected individuals and there was evidence of disease progression, albeit in a single case. A further MCDRl-like macular dystrophy associated with deafness has also been described recently. ${ }^{85}$

\section{Progressive bifocal chorioretinal atrophy (PBCRA)}

PBCRA is an autosomal dominant disorder characterised by nystagmus, myopia and progressive macular and nasal retinal atrophic lesions. ${ }^{86}$ Marked photopsia in early/middle age and retinal detachment extending from the posterior pole are recognised complications. ${ }^{87}$ Both ERG and EOG are abnormal, reflecting widespread abnormality of photoreceptors and RPE.

PBCRA has been linked to 6ql4-q16.2. ${ }^{88}$ The PBCRA disease interval overlaps with the established MCDRI interval. These two autosomal dominant macular dystrophies have many phenotypic similarities. However PBCRA differs significantly from MCDRl in several important ways, including slow progression, abnormal colour vision, extensive nasal as well as macular atrophy and abnormal ERG and EOG. Therefore, if allelic, it is likely that different mutations are involved in their aetiology. An alternative explanation is that PBCRA and MCDRl are caused by mutations in two different adjacent genes.

\section{Sorsby fundus dystrophy}

Sorsby fundus dystrophy (SFD) is a rare, autosomal dominant macular dystrophy, with onset of night blindness in the third decade and loss of central vision from macular atrophy or SRNVM by the fifth decade (fig 5). A tritan colour vision defect has been previously suggested as an early sign in SFD. ${ }^{89}$

The tissue inhibitor of metalloproteinase-3 (TIMP3) gene on chromosome 22q) is implicated in SFD. ${ }^{90-92}$ Most of the known mutations in TIMP3, including Ser181Cys, ${ }^{90}$ Ser156Cys, ${ }^{11}$ and Tyr172Cys, ${ }^{92}$ introduce potentially unpaired cysteine residues in the $\mathrm{C}$-terminus of the protein, thereby resulting in inappropriate disulfide bond formation and an abnormal tertiary protein structure. This may alter TIMP3 mediated extracellular matrix turnover leading to the

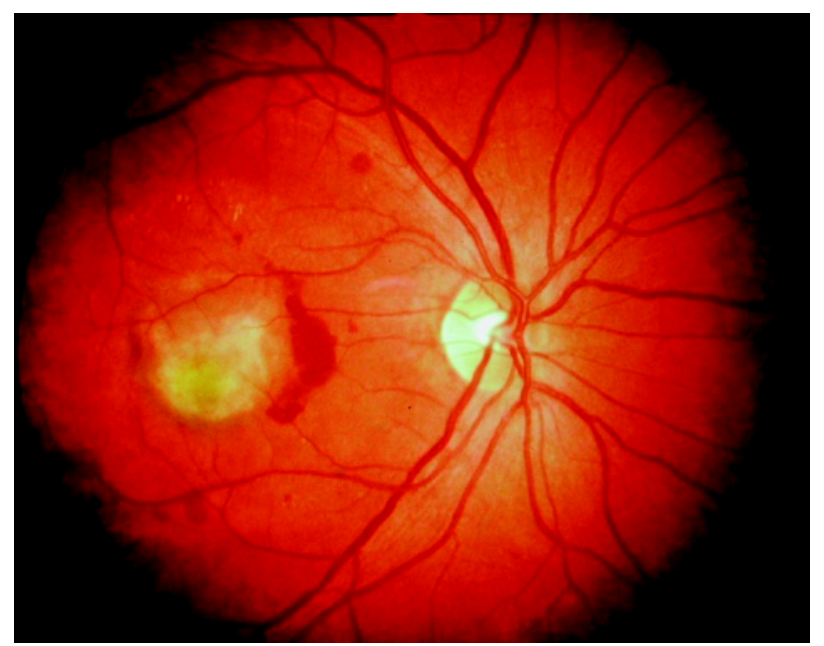

Figure 5 Sorsby fundus dystrophy. Fundus photograph of a right eye showing subretinal haemorrhage as a complication of choroidal neovascularisation, in a 45 year old woman carrying the Ser 156 Cys mutation in TIMP3.

thickening of Bruch's membrane and the widespread accumulation of abnormal material beneath the RPE that is seen histologically. ${ }^{93}{ }^{94}$ The finding that treatment with high doses of oral vitamin A reverses night blindness in this disorder, ${ }^{95}$ suggests that retinal dysfunction may be due to a reduction in the permeability of Bruch's membrane, resulting in the hindrance of transport of vitamin A from the choriocapillaris to the photoreceptors by accumulated extracellular debris beneath the RPE. In addition, Majid et $a l^{96}$ have demonstrated that mutant TIMP3 can induce apoptosis of RPE cells suggesting that apoptosis may be the final pathway for cell death in this disorder. Furthermore, TIMP3 has been recently shown to be a potent inhibitor of angiogenesis, which may account for the recognised complication of choroidal neovascularisation seen in SFD. ${ }^{97}$ TIMP3 inhibits vascular endothelial growth factor (VEGF)mediated angiogenesis, most probably by blockade of VEGF-2 receptors. ${ }^{97}$

Further insights into the pathophysiology of SFD may follow the development of a knock-in mouse carrying a disease-related Ser156Cys mutation in the orthologous murine TIMP3 gene. ${ }^{98}$ Immunolabeling studies and biochemical data from these mice suggested that site specific excess rather than absence or deficiency of functional TIMP3 may be the primary consequence of the known TIMP3 mutations.

\section{Central areolar choroidal dystrophy (CACD)}

CACD is characterised by bilateral, symmetrical, subtle mottling of the RPE at the macula in the early stages. The mottling then progresses to atrophy of the RPE and choriocapillaris. ${ }^{99}$

An Arg 142Trp mutation in peripherin/RDS has been implicated as one cause of this rare autosomal dominant macular dystrophy. ${ }^{100}$ Sporadic cases of CACD have also been described but no mutations were found in peripherin/RDS. ${ }^{100}$ A second locus at chromosome 17pl3 has also been identified by a genome wide linkage search in a large Northern Irish family. ${ }^{101} 102$

\section{Dominant cystoid macular dystrophy (dominant cystoid macular oedema)}

This rare autosomal dominantly inherited macular dystrophy was first described by Deutman et al. ${ }^{103}$ Cystoid macular oedema with leaking perifoveal capillaries on fluorescein angiography is seen in all affected patients. Other features include onset usually in the fourth decade, typically a 
moderate to high hypermetropic refractive error, and a normal ERG. ${ }^{103}{ }^{104}$ Genetic linkage has been established to 7p15-p21. ${ }^{105}$ The causative gene remains to be identified.

In addition to those described above there are several other autosomal dominant macular dystrophies whose phenotypes are not well described.

\section{$X$ LINKED INHERITANCE}

\section{$X$ linked juvenile retinoschisis (XLRS)}

XLRS is a vitreoretinal degeneration which presents either in an infant with nystagmus, or more commonly in childhood with mild loss of central vision. ${ }^{106}$ The characteristic fundus abnormality is a cystic spokewheel-like maculopathy (foveal schisis) in virtually all affected males (fig 6). Peripheral retinal abnormalities including bilateral schisis cavities, vascular closure, inner retinal sheen, and pigmentary retinopathy are seen in approximately $50 \%$ of cases. ${ }^{107}$ Flash ERG typically reveals a negative waveform, in that the a-wave is larger in amplitude than the b-wave. Prognosis is good in most affected males as long as retinal detachment or vitreous haemorrhage does not occur. The histopathological findings in XLRS include splitting within the superficial layers of the retina, degeneration of photoreceptors, thinning of the ganglion cell layer, and a focally absent or proliferative RPE. ${ }^{108} 109$

XLRS has been linked to Xp22.2 and mutations in the gene $X L R S 1$ (also recently referred to as $R S I$ ) have been identified. ${ }^{110}$ Juvenile retinoschisis shows a wide variability in the phenotype between, as well as within, families with different genotypes. ${ }^{111}$ XLRS1 encodes a 224 amino acid protein, retinoschisin (RS1), which contains a highly conserved discoidin domain implicated in cell-cell adhesion and cell-matrix interactions, functions which correlate well with the observed splitting of the retina in XLRS.

Many missense and protein truncating mutations of XLRSI have now been identified and are thought to be inactivating. ${ }^{12}$ It has been demonstrated that although XLRSI is expressed predominantly in photoreceptors, ${ }^{113}{ }^{114}$ it is also expressed in bipolar cells. ${ }^{114}$ RSI is assembled in photoreceptors of the outer retina and bipolar cells of the inner retina as a disulfide-linked oligomeric protein complex. The secreted complex associates with the surface of these cells, where it may function as a cell adhesion protein to maintain the integrity of the central and peripheral retina. ${ }^{114}$ To gain further insight into the function of the retinoschisin protein, knockout mice have been generated, deficient in RsIh, the

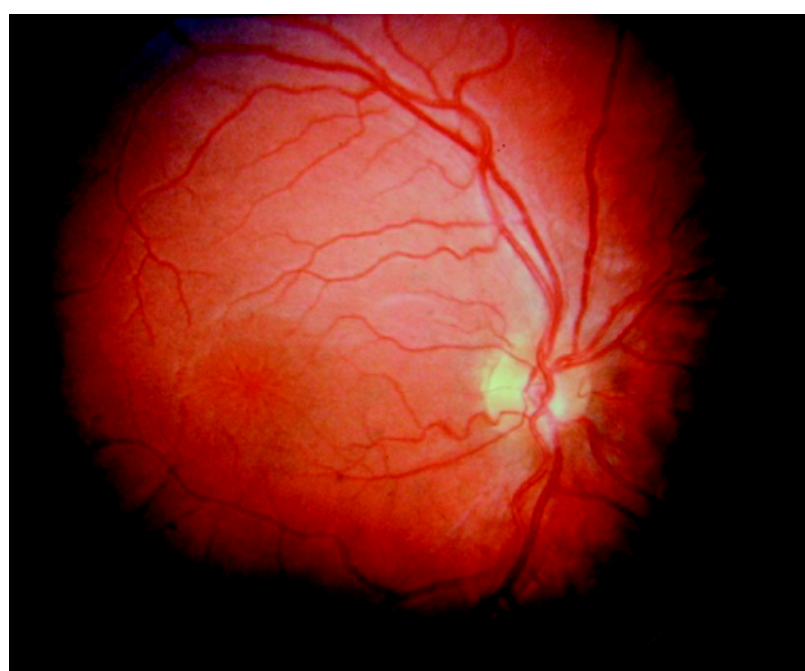

Figure $6 \mathrm{X}$ linked juvenile retinoschisis. Fundus photograph of a right eye showing the characteristic fundus abnormality of a cystic spokewheel-like maculopathy (foveal schisis). murine orthologue of the human XLRSI gene. ${ }^{115}$ The hemizygous $R s i h^{-/ Y}$ male mouse was shown to share several diagnostic features with human XLRS, including the typical "negative ERG" response and the development of cystic structures within the inner retina, followed by a dramatic loss of photoreceptor cells. Whilst the major pathology in the retina of the retinoschisin deficient mouse seemed to be a generalised disruption of cell layer architecture, atypical ribbon synapse formation at the photoreceptor terminals was also noted. This suggests a direct or indirect role of RSI in the assembly and stabilisation of this synaptic region of the cell. ${ }^{115}$ Failure to establish or maintain these synaptic connections could lead to subsequent photoreceptor cell death.

\section{MITOCHONDRIAL INHERITANCE}

\section{Maternally inherited diabetes and deafness (MIDD)}

MIDD is a recently described subtype of diabetes mellitus that co-segregates with an adenine-to-guanine transition at position 3243 of mitochondrial DNA (A3243G), in a transfer RNA leucine (tRNALeu (UUR)) encoding region. ${ }^{116} 117$ This mitochondrial DNA mutation can also be associated with a severe encephalopathy with death at a young age (MELAS: mitochondrial encephalomyopathy with lactic acidosis and stroke-like episodes). ${ }^{118}$

Macular pattern dystrophy (MPD) has been found in association with MIDD. ${ }^{119}$ In a multicentre study, $86 \%$ of MIDD patients were found to have bilateral MPD, characterised by RPE hyperpigmentation that can surround the macula or be more extensive and also encompass the optic disc. ${ }^{120}$ In advanced cases areas of RPE atrophy encircling the macula can be seen, which may coalesce and involve the fovea at a late stage (fig 7). However prognosis is generally good, with $80 \%$ of patients in the multicentre study having visual acuity of $6 / 7.5$ or better in both eyes. ${ }^{120}$ As the prevalence of MPD in MIDD is high, the association of a MPD with diabetes should raise the possibility of screening for a mutation of mitochondrial DNA.

\section{AGE RELATED MACULAR DEGENERATION}

ARMD is by far the most common form of macular degeneration. ARMD is the leading cause of blindness in patients over the age of 65 years in the western world. Despite its prevalence, its aetiology and pathogenesis are still poorly understood, and, currently, effective treatment options are limited for the majority of patients.

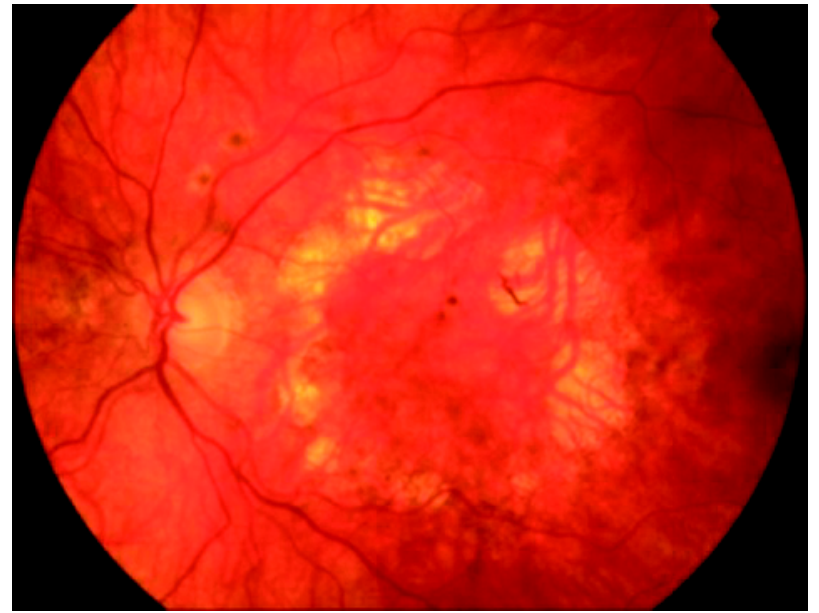

Figure 7 Maternally inherited diabetes and deafness. Fundus photograph of a left eye showing areas of macular atrophy surrounding the macula, through which underlying choroidal vessels are visible. This patient was found to be carrying the adenine-to-guanine transition at position 3243 of mitochondrial DNA (A3243G). 
ARMD has a genetic contribution to its aetiology. Putative susceptibility loci have been identified on chromosome lq25$\mathrm{q} 31^{121}{ }^{122}$ chromosome $17 \mathrm{q} 25^{122}$ and on chromosomes 5, 9, and $10,{ }^{123}$ whereas it has been suggested that the e 4 allele of the apolipoprotein E gene and an Alu polymorphism in the angiotensin-converting enzyme gene may have a protective effect on ARMD risk. ${ }^{124} 125$

Inherited monogenic macular dystrophies share many important features with ARMD and have the advantage that they are more readily studied. One of the major difficulties in studies of ARMD is its late onset. Parents of affected individuals are often deceased and their children have yet to manifest the disease. In contrast, there are several forms of macular dystrophy, such as STGD/FFM, Best disease and MCDR1, which manifest signs and symptoms at an early age. These dystrophies and others have been characterised in large numbers of family members, spanning several generations, thereby making them far more amenable to genetic analysis. Furthermore, several of these macular dystrophies share many important clinical and histopathological similarities with ARMD, including an abnormal accumulation of lipofuscin in the RPE and a concomitant loss of function of overlying photoreceptors and central vision. ${ }^{126}{ }^{127}$

However to date, with the possible exception of $A B C A 4$, none of these genes have been shown to confer increased risk of ARMD. ${ }^{44} 7^{123}{ }^{128-132}$ However, all new macular dystrophy genes represent good candidates for ARMD.

\section{CONCLUSIONS}

Although in some inherited macular dystrophies, the disease is confined to the macular region, in other disorders, perhaps the majority, there is electrophysiological, psychophysical, or histological evidence of widespread retinal dysfunction. This may partly account for the fact that to date, genes implicated in monogenic macular dystrophies have not been found to have a significant role in the genetic predisposition to ARMD.

Another possible reason for the lack of significant ARMD association with variation in the monogenic macular dystrophy genes so far identified is the hypothesis that the coincidence of subclinical mutations in a number of genes involved in the formation and function of the macula could be responsible in a polygenic fashion for cases of ARMD. However, it also remains a possibility that the susceptibility genes are neither specifically retinal nor macular.

Improved knowledge of the mechanisms of inherited macular dystrophy and the underlying molecular genetics, has not only raised the potential for future development of rational therapeutic regimens, but has helped to refine diagnosis, disease classification and prognosis, and improved genetic counselling.

\section{ACKNOWLEDGEMENTS}

We thank Professor A Bird for permission to reproduce the fundal photo used as an example of North Carolina macular dystrophy.

\section{Authors' affiliations \\ M Michaelides, D M Hunt, A T Moore, Institute of Ophthalmology, University College London, London, UK}

\section{REFERENCES}

1 Klaver CC, Wolfs RC, Assink JJ, et al. Genetic risk of age-related maculopathy. Population-based familial aggregation study. Arch Ophthalmol 1998;116:1646-51.

2 Meyers SM, Zachary AA. Monozygotic twins with age-related macular degeneration. Arch Ophthalmol 1988;106:651-3.

3 Fish G, Grey R, Sehmi KS, et al. The dark choroid in posterior retinal dystrophies. Br J Ophthalmol 1981;65:359-63.

4 Fishman GA, Farber M, Patel BS, et al. Visual acuity loss in patients with Stargardt's macular dystrophy. Ophthalmology 1987;94:809-14.
5 von Rückmann A, Fitzke FW, Bird AC. Distribution of fundus autofluorescence with a scanning laser ophthalmoscope. Br J Ophthalmol 1995;79:407-12.

6 von Rückmann A, Fitzke FW, Bird AC. In vivo fundus autofluorescence in macular dystrophies. Arch Ophthalmol 1997;115:609-15.

7 von Rückmann A, Fitzke FW, Bird AC. Distribution of pigment epithelium autofluorescence in retinal disease state recorded in vivo and its change over time. Graefe's Arch Clin Exp Ophthalmol 1999;237:1-9.

8 von Rückmann A, Fitzke FW, Bird AC. Fundus autofluorescence in age related macular disease imaged with a scanning laser ophthalmoscope. Invest Ophthalmol Vis Sci 1997;38:478-86.

9 Dorey CK, Wu G, Ebenstein D, et al. Cell loss in the ageing retina: relationship to lipofuscin accumulation and macular degeneration. Invest Ophthalmol Vis Sci 1989;30:1691-9.

10 Lois N, Holder GE, Bunce C, et al. Phenotypic subtypes of Stargardt macular dystrophy-fundus flavimaculatus. Arch Ophthalmol 2001;119:359-69

11 Eagle RC, Lucier AC, Bernardino VB, et al. Retinal pigment epithelial abnormalities in fundus flavimaculatus: a light and electron microscopic study. Ophthalmology 1980;87:1189-200.

12 Birnbach CD, Jarvelainen M, Possin DE, et al. Histopathology and immunocytochemistry of the neurosensory retina in fundus flavimaculatus. Ophthalmology 1994;101:1211-19.

13 Kaplan J, Gerber S, Larget-Piet D, et al. A gene for Stargardt's disease (fundus flavimaculatus) maps to the short arm of chromosome 1. Nat Genet 1993;5:308-11.

14 Allikmets R, Singh N, Sun H, et al. A photoreceptor cell-specific ATP-binding transporter gene $(A B C R)$ is mutated in recessive Stargardt macular dystrophy. Nat Genet 1997; 15:236-46.

15 Martinez-Mir A, Bayes M, Vilageliu L, et al. A new locus for autosomal recessive retinitis pigmentosa (RP19) maps to 1p13-1p21. Genomics 1997;40:142-6.

16 Martinez-Mir A, Paloma E, Allikmets R, et al. Retinitis pigmentosa caused by a homozygous mutation in the Stargardt disease gene $A B C R$. Nat Genet 1998; 18:11-12.

17 Cremers FP, van de Pol DJ, van Driel M, et al. Autosomal recessive retinitis pigmentosa and cone-rod dystrophy caused by splice site mutations in the Stargardt's disease gene ABCR. Hum Mol Genet 1998;7:355-62.

18 Maugeri A, Klevering BJ, Rohrschneider K, et al. Mutations in the ABCA4 $(A B C R)$ gene are the major cause of autosomal recessive cone-rod dystrophy. Am J Hum Genet 2000;67:960-6.

19 Sun H, Nathans J. Stargardt's ABCR is localized to the disc membrane of retinal rod outer segments. Nat Genet 1997;17:15-16.

20 Molday LL, Rabin AR, Molday RS. ABCR expression in foveal cone photoreceptors and its role in stargardt macular dystrophy. Nat Genet 2000;25:257-8.

21 Weng J, Mata NL, Azarian SM, et al. Insights into the function of Rim protein in photoreceptors and etiology of Stargardt's disease from the phenotype in abcr knockout mice. Cell 1999;98:13-23.

22 Rozet JM, Gerber S, Souied E, et al. Spectrum of $A B C R$ gene mutations in autosomal recessive macular dystrophies. Eur J Hum Genet 1998;6:291-5.

23 Maugeri A, van Driel MA, van de Pol DJ, et al. The $2588 \mathrm{G} \rightarrow C$ mutation in the $A B C R$ gene is a mild frequent founder mutation in the Western European population and allows the classification of $A B C R$ mutations in patients with Stargardt disease. Am J Hum Genet, 1999;64, 1024-35.

24 Rivera A, White $\mathrm{K}$, Stohr $\mathrm{H}$, et al. A comprehensive survey of sequence variation in the $A B C A 4(A B C R)$ gene in Stargardt disease and age-related macular degeneration. Am J Hum Genet 2000;67:800-13.

25 Simonelli $F$, Testa $F$, de Crecchio $G$, et al. New $A B C R$ mutations and clinical phenotype in Italian patients with Stargardt disease. Invest Ophthalmol Vis Sci 2000;41:892-7

26 Webster AR, Heon E, Lotery AJ, et al. An analysis of allelic variation in the ABCA4 gene. Invest Ophthalmol Vis Sci 2001;42:1179-89.

27 Sun H, Smallwood PM, Nathans J, et al. Biochemical defects in ABCR protein variants associated with human retinopathies. Nat Genet 2000;26:242-6.

28 van Driel MA, Maugeri A, Klevering BJ, et al. ABCR unites what ophthalmologists divide(s). Ophthalmic Genet 1998;19:117-22.

29 Gerth C, Andrassi-Darida M, Bock M, et al. Phenotypes of 16 Stargardt macular dystrophy/fundus flavimaculatus patients with known $A B C A 4$ mutations and evaluation of genotype-phenotype correlation. Graefes Arch Clin Exp Ophthalmol 2002;240:628-38.

30 Lois N, Holder GE, Fitzke FW, et al. Intrafamilial variation of phenotype in Stargardt macular dystrophy-Fundus flavimaculatus. Invest Ophthalmol Vis Sci 1999;40:2668-75.

31 Paloma E, Coco R, Martinez-Mir A, et al. Analysis of ABCA4 in mixed Spanish families segregating different retinal dystrophies. Hum Mutat 2002;20:476-83

32 Fishman GA, Farbman JS, Alexander KR. Delayed rod dark adaptation in patients with Stargardt's disease. Ophthalmology 1991;98:957-62.

33 Steinmetz RL, Haimovici R, Jubb C, et al. Symptomatic abnormalities of dark adaptation in patients with age-related Bruch's membrane change. Br J Ophthalmol 1993;77:549-54.

34 Mata NL, Tzekov RT, Liu X, et al. Delayed dark-adaptation and lipofuscin accumulation in abcr+/- mice: implications for involvement of $A B C R$ in agerelated macular degeneration. Invest Ophthalmol Vis Sci 2001;42:1685-90.

35 Sparrow JR, Nakanishi K, Parish CA. The lipofuscin fluorophore A2E mediates blue light-induced damage to retinal pigmented epithelial cells. Invest Ophthalmol Vis Sci 2000;41:1981-9.

36 Sparrow JR, Zhou J, Ben-Shabat S, et al. Involvement of oxidative mechanisms in blue-light-induced damage to A2E-laden RPE. Invest Ophthalmol Vis Sci 2002;43:1222-7. 
37 Sparrow JR, Vollmer-Snarr HR, Zhou J, et al. A2E-epoxides damage DNA in retinal pigment epithelial cells. Vitamin $\mathrm{E}$ and other antioxidants inhibit $\mathrm{A} 2 \mathrm{E}$ epoxide formation. J Biol Chem 2003;(in press).

38 Sun H, Molday RS, Nathans J. Retinal stimulates ATP hydrolysis by purified and reconstituted $A B C R$, the photoreceptor-specific ATP-binding cassette transporter responsible for Stargardt disease. J Biol Chem 1999:274:8269-81

39 Mata NL, Weng J, Travis GH. Biosynthesis of a major lipofuscin fluorophore in mice and humans with $A B C R$-mediated retinal and macular degeneration. Proc Natl Acad Sci U S A 2000;97:7154-9.

40 Radu RA, Mata NL, Nusinowitz S, et al. Treatment with isotretinoin inhibits lipofuscin accumulation in a mouse model of recessive Stargardt's macular degeneration. Proc Natl Acad Sci U S A 2003;100:4742-7.

41 Donoso LA, Edwards AO, Frost A, et al. Autosomal dominant Stargardt-like macular dystrophy. Surv Ophthalmol 2001:46:149-63.

42 Stone EM, Nichols BE, Kimura AE, et al. Clinical features of a Stargardt-like dominant progressive macular dystrophy with genetic linkage to chromosome 6q. Arch. Ophthal 1994;112:765-72.

43 Kniazeva M, Chiang MF, Morgan B, et al. A new locus for autosomal dominant Stargardt-like disease maps to chromosome 4. Am J Hum Genet 1999;64:1394-9.

44 Zhang K, Kniazeva M, Han M, et al. A 5-bp deletion in ELOVL4 is associated with two related forms of autosomal dominant macular dystrophy. Nat Genet 2001;27:89-93.

45 Bernstein PS, Tammur J, Singh N, et al. Diverse macular dystrophy phenotype caused by a novel complex mutation in the ELOVL4 gene. Invest Ophthalmol Vis Sci 2001;42:3331-6.

46 Maw MA, Corbeil D, Koch J, et al. A frameshift mutation in prominin (mouse)-like 1 causes human retinal degeneration. Hum Mol Genet 2000;9:27-34

47 Michaelides M, Johnson S, Poulson A, et al. An Autosomal Dominant Bull'sEye Macular Dystrophy (MCDR2) that maps to the short arm of chromosome 4. Invest Ophthalmol Vis Sci 2003:44:1657-62.

48 Deutman AF. Electro-oculography in families with vitelliform dystrophy of the fovea. Detection of the carrier state. Arch Ophthalmol 1969;81:305-16.

49 Weingeist TA, Kobrin JL, Watzke RC. Histopathology of Best's macular dystrophy. Arch Ophthalmol 1982;100:1108-14.

50 Frangieh GT, Green WR, Fine SL. A histopathologic study of Best's macular dystrophy. Arch Ophthalmol 1982;100:1115-21.

51 Forsman K, Graff C, Nordstrom S, et al. The gene for Best's macular dystrophy is located at 11 q13 in a Swedish family. Clin Genet 1992:42:156-9.

52 Petrukhin K, Koisti MJ, Bakall B, et al. Identification of the gene responsible for Best macular dystrophy. Nat Genet 1998;19:241-7.

53 Caldwell GM, Kakuk LE, Griesinger TB, et al. Bestrophin gene mutations in patients with Best vitelliform macular dystrophy. Genomics 1999;58:98-101

54 Mohler CW, Fine SL. Long-term evaluation of patients with Best's vitelliform dystrophy. Ophthalmology 1981;88:688-92.

55 Weber BH, Walker D, Muller B. Molecular evidence for non-penetrance in Best's disease. J Med Genet 1994;31:388-92.

56 Marmorstein AD, Marmorstein LY, Rayborn M, et al. Bestrophin, the product of the Best vitelliform macular dystrophy gene (VMD2), localizes to the basolateral plasma membrane of the retinal pigment epithelium. Proc Natl Acad Sci U S A 2000;97:12758-63.

57 Sun H, Tsunenari T, Yau KW, et al. The vitelliform macular dystrophy protein defines a new family of chloride channels. Proc Natl Acad Sci U S A 2002:99:4008-13.

58 Pianta MJ, Aleman TS, Cideciyan AV, et al. In vivo micropathology of Best macular dystrophy with optical coherence tomography. Exp Eye Res 2003;76:203-11.

59 Bird AC. Pathogenesis of serous detachment of the retina and pigment epithelium. In: Ryan SJ, eds. Retina, 2.St. Louis: Mosby, 1994:1019-26.

60 Fisher SK, Stone J, Rex TS, et al. Experimental retinal detachment: a paradigm for understanding the effects of induced photoreceptor degeneration. Prog Brain Res 2001;131:679-98.

61 Brecher R, Bird AC. Adult vitelliform macular dystrophy. Eye 1990;4:210-15.

62 Felbor U, Schilling $\mathrm{H}$, Weber BHF. Adult vitelliform macular dystrophy is frequently associated with mutation in the peripherin/RDS gene. Hum Mutat 1997:10:301-9.

63 Kemp CM, Jacobson SG, Cideciyan AV, et al. RDS gene mutations causing retinitis pigmentosa or macular degeneration lead to the same abnormality in photoreceptor function. Invest Ophthalmol Vis Sci 1994;35:3154-62.

64 Nichols BE, Sheffield VC, Vandenburgh K, et al. Butterfly-shaped pigment dystrophy of the fovea caused by a point mutation in codon 167 of the RDS gene. Nat Genet 1993;3:202-7.

65 Nichols BE, Drack AV, Vandenburgh K, et al. A 2 base pair deletion in the $R D S$ gene associated with butterfly-shaped pigment dystrophy of the fovea. Hum Mol Genet 1993;2:601-3.

66 Weleber RG, Carr RE, Murphy WH, et al. Phenotypic variation including retinitis pigmentosa, pattern dystrophy, and fundus flavimaculatus in a single family with a deletion of codon 153 or 154 of the peripherin/RDS gene. Arch Ophthalmol 1993;111:1531-42.

67 Farrar GJ, Kenna P, Jordan SA, et al. A three-base-pair deletion in the peripherin-RDS gene in one form of retinitis pigmentosa. Nature 1991:354:478-80.

68 Kajiwara K, Hahn LB, Mukai S, et al. Mutations in the human retinal degeneration slow gene in autosomal dominant retinitis pigmentosa. Nature $1991 ; 354: 480-3$.
69 Downes SM, Fitzke FW, Holder GE, et al. Clinical features of codon 172 RDS macular dystrophy: similar phenotype in 12 families. Arch Ophthalmol 1999:117:1373-83.

70 Travis GH, Sutcliffe JG, Bok D. The retinal degeneration slow (rds) gene product is a photoreceptor disc membrane-associated glycoprotein. Neuron 1991:6:61-70.

71 Poetsch A, Molday LL, Molday RS. The cGMP-gated channel and related glutamic acid-rich proteins interact with peripherin-2 at the rim region of rod photoreceptor disc membranes. J Biol Chem 2001;276:48009-16.

72 Ali RR, Sarra GM, Stephens C, et al. Restoration of photoreceptor ultrastructure and function in retinal degeneration slow mice by gene therapy. Nature Genet 2000;25:306-10.

73 Sarra GM, Stephens C, de Alwis M, et al. Gene replacement therapy in the retinal degeneration slow (rds) mouse: the effect on retinal degeneration following partial transduction of the retina. Hum Molec Genet $2001 ; 10: 2353-61$

74 Stone EM, Lotery AJ, Munier FL, et al. A single EFEMPI mutation associated with both malattia Leventinese and Doyne honeycomb retinal dystrophy. Nature Genet 1999:22:199-202.

75 Marmorstein LY, Munier FL, Arsenijevic Y, et al. Aberrant accumulation of EFEMPI underlies drusen formation in Malattia Leventinese and age-related macular degeneration. Proc Natl Acad Sci U S A 2002;99:13067-72.

76 Tarttelin EE, Gregory-Evans CY, Bird AC, et al. Molecular genetic heterogeneity in autosomal dominant drusen. J Med Genet 2001;38:381-4.

77 Stefko ST, Zhang K, Gorin MB et al. Clinical spectrum of chromosome 6linked autosomal dominant drusen and macular degeneration. Am J Ophthalmol 2000;130:203-8.

78 Kniazeva M, Traboulsi El, Yu Z, et al. A new locus for dominant drusen and macular degeneration maps to chromosome 6ql4. Am J Ophthalmol 2000; 130: 197-202.

79 Griesinger IB, Sieving PA, Ayyagari R. Autosomal dominant macular atrophy at 6q14 excludes CORD7 and MCDR1/PBCRA loci. Invest Ophthalmol Vis Sci 2000:41:248-55.

80 Small KW. North Carolina macular dystrophy: clinical features, genealogy, and genetic linkage analysis. Trans Am Ophthalmol Soc 1998;96:925-61.

81 Small KW, Udar N, Yelchits S, et al. North Carolina macular dystrophy (MCDR1) locus: A fine resolution genetic map and haplotype analysis. Mo Vis 1999;5:38-42.

82 Reichel MB, Kelsell RE, Fan J, et al. Phenotype of a British North Carolina macular dystrophy family linked to chromosome 6q. $\mathrm{Br} J$ Ophthalmol 1998:82:1162-8.

83 Rabb MF, Mullen L, Yelchits S, et al. A North Carolina macular dystrophy phenotype in a Belizean family maps to the MCDR1 locus. Am J Ophthalmo 1998; 125:502-8

84 Michaelides $M$, Johnson S, Tekriwal AK, et al. An early-onset autosomal dominant macular dystrophy (MCDR3) resembling North Carolina macular dystrophy maps to chromosome 5. Invest Ophthalmol Vis Sci 2003;44:2178-83

85 Francis PJ, Johnson S, Edmunds B, et al. Genetic linkage analysis of a novel syndrome comprising North Carolina-like macular dystrophy and progressive sensorineural hearing loss. Br J Ophthalmol 2003;87:893-8

86 Douglas AA, Waheed I, Wyse CT. Progressive bifocal chorio-retinal atrophy. A rare familial disease of the eyes. $\mathrm{Br} J$ Ophthalmol 1968:52:742-51.

87 Godley BF, Tiffin PA, Evans K, et al. Clinical features of progressive bifocal chorioretinal atrophy: a retinal dystrophy linked to chromosome 6q. Ophthalmology 1996;103:893-8.

88 Kelsell RE, Godley BF, Evans K, et al. Localization of the gene for progressive bifocal chorioretinal atrophy (PBCRA) to chromosome 6q. Hum Mol Genet 1995;4:1653-6.

89 Berninger TA, Polkinghorne PJ, Capon MR, et al. Color vision defect. A early sign of Sorsby retinal dystrophy? Ophthalmologe 1993:90:515-18.

90 Weber BH, Vogt G, Pruett RC, et al. Mutations in the tissue inhibitor of metalloproteinases-3 (TIMP3) in patients with Sorsby's fundus dystrophy. Nat Genet 1994;8:352-6.

91 Felbor U, Stohr H, Amann T, et al. A novel Ser156Cys mutation in the tissue inhibitor of metalloproteinases-3 (TIMP3) in Sorsby's fundus dystrophy with unusual clinical features. Hum Mol Genet 1995;4:2415-16.

92 Jacobson SG, Cideciyan AV, Bennett J, et al. Novel mutation in the TIMP3 gene causes Sorsby fundus dystrophy. Arch Ophthalmol 2002;120:376-9.

93 Chong NH, Alexander RA, Gin T, et al. TIMP-3, collagen, and elastin immunohistochemistry and histopathology of Sorsby's fundus dystrophy. Invest Ophthalmol Vis Sci 2000;41:898-902.

94 Capon MR, Marshall J, Krafft Jl, et al. Sorsby's fundus dystrophy. A light and electron microscopic study. Ophthalmology 1989:96:1769-77.

95 Jacobson SG, Cideciyan AV, Regunath G, et al. Night blindness in Sorsby's fundus dystrophy reversed by vitamin A. Nat Genet 1995;11:27-32

96 Majid MA, Smith VA, Easty DL, et al. Sorsby's fundus dystrophy mutant tissue inhibitors of metalloproteinase-3 induce apoptosis of retinal pigment epithelial and MCF-7 cells. FEBS Lett 2002;529:281-5.

97 Qi JH, Ebrahem Q, Moore N, et al. A novel function for tissue inhibitor of metalloproteinases-3 (TIMP3): inhibition of angiogenesis by blockage of VEGF binding to VEGF receptor-2. Nat Med 2003;9:407-15.

98 Weber BH, Lin B, White K, et al. A mouse model for Sorsby fundus dystrophy. Invest Ophthalmol Vis Sci 2002;43:2732-40.

99 Hoyng CB, Deutman AF. The development of central areolar choroida dystrophy. Graefes Arch Clin Exp Ophthalmol 1996;234:87-93.

100 Hoyng CB, Heutink P, Testers L, et al. Autosomal dominant central areolar choroidal dystrophy caused by a mutation in codon 142 in the peripherin/ RDS gene. Am J Ophthalmol 1996;121:623-9. 
101 Lotery AJ, Ennis KT, Silvestri G, et al. Localisation of a gene for central areolar choroidal dystrophy to chromosome 17p. Hum Mol Genet 1996:5:705-8

102 Hughes AE, Lotery AJ, Silvestri G. Fine localisation of the gene for central areolar choroidal dystrophy on chromosome 17p. J Med Genet 1998:35:770-2.

103 Deutman AF, Pinckers AJL, Aan de Kerk AL. Dominantly inherited cystoid macular oedema. Am J Ophthal 1976;82:540-8.

104 Pinckers A, Deutman AF, Lion F, et al. Dominant cystoid macular dystrophy (DCMD). Ophthal Paediat Genet 1983;3:157-67.

105 Kremer H, Pinckers A, van den Heim B, et al. Localization of the gene for dominant cystoid macular dystrophy on chromosome 7p. Hum Molec Genet 1994;3:299-302.

106 George ND, Yates JR, Bradshaw K, et al. Infantile presentation of X linked retinoschisis. Br J Ophthalmol 1995;79:653-657.

107 George ND, Yates JR, Moore AT. X linked retinoschisis. Br J Ophthalmol 1995;79:697-702.

108 Yanoff M, Rahn EK, Zimmerman LE. Histopathology of juvenile retinoschisis. Arch Ophthalmol 1968;79:49-53.

109 Manschot WA. Pathology of hereditary juvenile retinoschisis. Arch Ophthalmol 1972;88:131-8.

110 Sauer CG, Gehrig A, Warneke-Wittstock R, et al. Positional cloning of the gene associated with X-linked juvenile retinoschisis. Nat Genet 1997; 17:164-70

111 Eksandh LC, Ponjavic V, Ayyagari R, et al. Phenotypic expression of juvenile $X$-linked retinoschisis in Swedish families with different mutations in the XLRS1 gene. Arch Ophthalmol 2000;118:1098-104.

112 The Retinoschisis Consortium. Functional implications of the spectrum of mutations found in 234 cases with X-linked juvenile retinoschisis. Hum Mo Genet 1998:7:1185-92.

113 Grayson C, Reid SN, Ellis JA, et al. Retinoschisin, the X-linked retinoschisis protein, is a secreted photoreceptor protein, and is expressed and released by Weri-Rbl cells. Hum Mol Genet 2000;9:1873-9.

114 Molday LL, Hicks D, Sauer CG, et al. Expression of X-linked retinoschisis protein RS1 in photoreceptor and bipolar cells. Invest Ophthalmol Vis Sci 2001;42:816-25

115 Weber BH, Schrewe H, Molday LL, et al. Inactivation of the murine X-linked juvenile retinoschisis gene, $R s \mathrm{~h}$, suggests a role of retinoschisin in retinal cell ayer organization and synaptic structure. Proc Natl Acad Sci U S A 2002;99:6222-7.

116 van den Ouweland JM, Lemkes HH, Ruitenbeek W, et al. Mutation in mitochondrial tRNA(Leu)(UUR) gene in a large pedigree with maternally transmitted type II diabetes mellitus and deafness. Nat Genet 1992;1:368-71.
117 Reardon W, Ross RJ, Sweeney MG, et al. Diabetes mellitus associated with a pathogenic point mutation in mitochondrial DNA. Lancet 1992:340:1376-9.

118 Goto Y, Nonaka I, Horai S. A mutation in the tRNA(Leu)(UUR) gene associated with the MELAS subgroup of mitochondrial encephalomyopathies. Nature 1990;348:651-3.

119 Massin P, Guillausseau PJ, Vialettes B, et al. Macular pattern dystrophy associated with a mutation of mitochondrial DNA. Am J Ophthalmol 1995; 120:247-8

120 Massin P, Virally-Monod M, Vialettes B, et al. Prevalence of macular pattern dystrophy in maternally inherited diabetes and deafness. GEDIAM Group. Ophthalmology 1999:106:1821-7.

121 Klein ML, Schultz DW, Edwards A, et al. Age-related macular degeneration. Clinical features in a large family and linkage to chromosome 1q. Arch Ophthalmol 1998;116:1082-8.

122 Weeks DE, Conley YP, Tsai HJ, et al. Age-related maculopathy: an expanded genome-wide scan with evidence of susceptibility loci within the $1 \mathrm{q} 31$ and 17q25 regions. Am J Ophthalmol 2001;132:682-92.

123 Weeks DE, Conley YP, Mah TS, et al. A full genome scan for age-related maculopathy. Hum Mol Genet 2000;9:1329-49.

124 Klaver CC, Kliffen M, van Duiin CM, et al. Genetic association of apolipoprotein E with age-related macular degeneration. Am J Hum Genet 1998;63:200-6.

125 Hamdi HK, Reznik J, Castellon R, et al. Alu DNA polymorphism in ACE gene is protective for age-related macular degeneration. Biochem Biophys Res Commun 2002;295:668-72.

126 Swann PG, Lovie-Kitchin. Age-related maculopathy. A review of its morphology and effects on visual function. Ophthalmol Physiol Opt 1990; 10:149-58.

127 Young RW. Pathophysiology of age-related macular degeneration. Surv Ophthalmol 1987;31:291-306.

128 Allikmets R, Shroyer NF, Singh N, et al. Mutation of the Stargardt disease gene $(A B C R)$ in age-related macular degeneration. Science 1997;277:1805-7.

129 Stone EM, Webster AR, Vandenburgh K, et al. Allelic variation in $A B C R$ associated with Stargardt disease but not age-related macular degeneration. Nat Genet 1998;20:328-9.

130 De La Paz MA, Guy VK, Abou-Donia S, et al. Analysis of the Stargardt disease gene $(A B C R)$ in age-related macular degeneration. Ophthalmology 1999:106:1531-6.

131 Lotery AJ, Munier FL, Fishman GA, et al. Allelic variation in the VMD2 gene in best disease and age-related macular degeneration. Invest Ophthalmol Vis Sci 2000;41:1291-6.

132 Stone EM, Sheffield VC, Hageman GS. Molecular genetics of age-related macular degeneration. Hum Mol Genet 2001;10:2285-92.

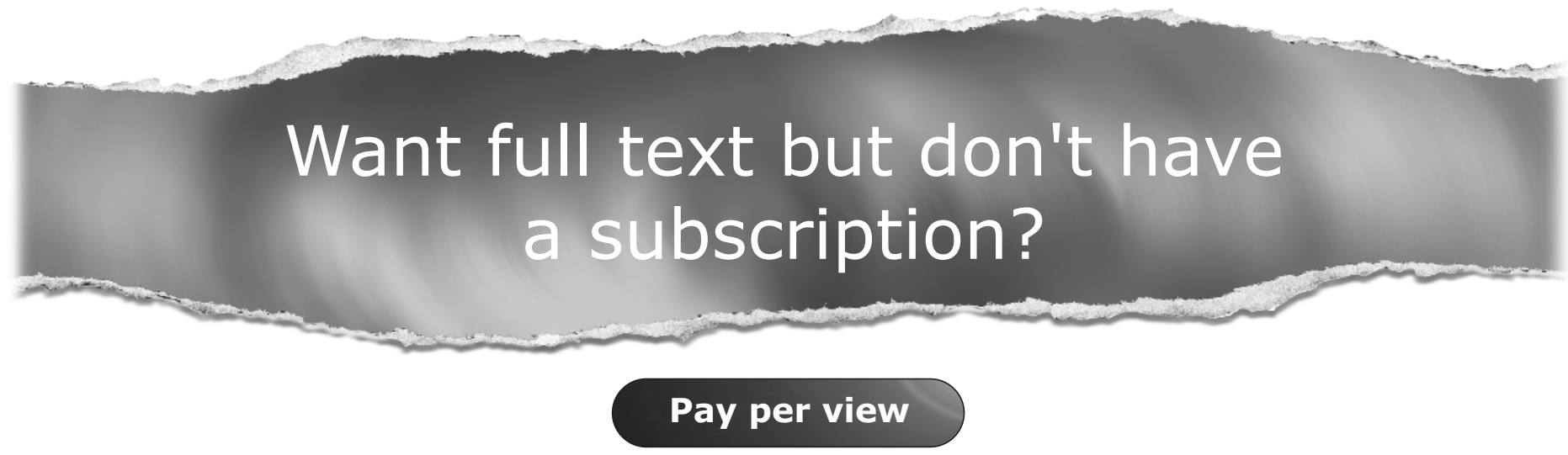

For just $\$ 8$ you can purchase the full text of individual articles using our secure online ordering service. You will have access to the full text of the relevant article for 48 hours during which time you may download and print the pdf file for personal use.

\section{www.jmedgenet.com}

